Hungarian Association of Agricultural Informatics

\title{
The water saving with Irriframe platform for thousands of Italian farms
}

\author{
Gianfranco Giannerini ${ }^{1}$, Roberto Genovesi ${ }^{2}$
}

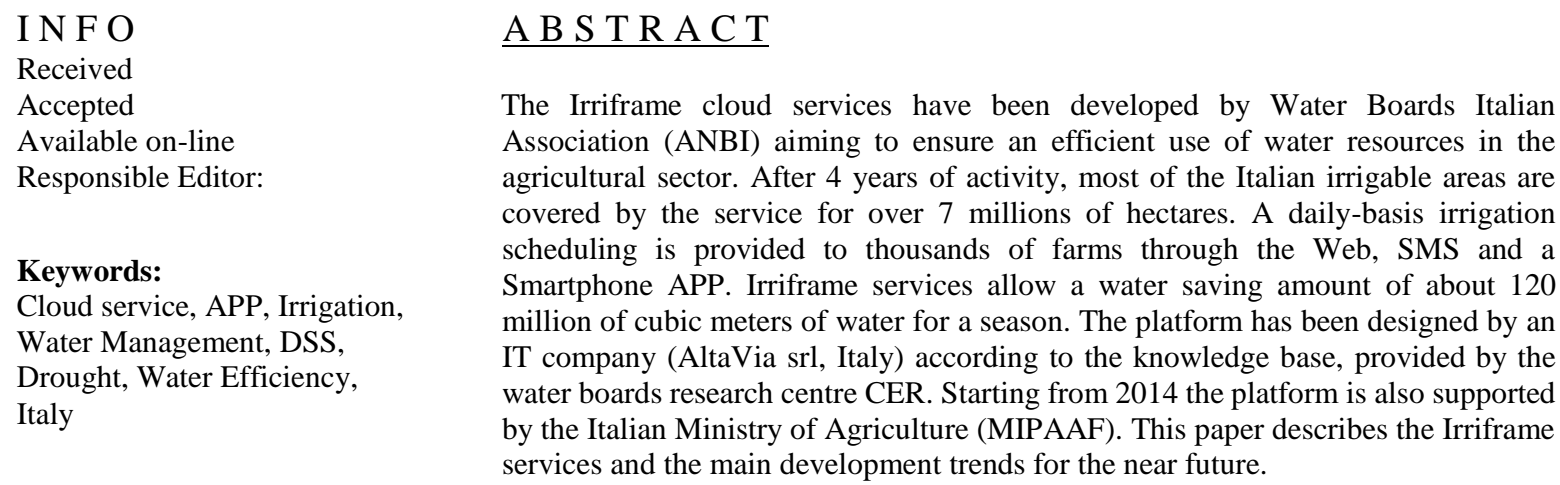

\section{Introduction}

$32 \%$ of Italian farms practice irrigation, with higher percentages in the North-West (62\%) and lower percentages in the Centre and South. Compared to 2005, irrigated farms increased by roughly 60,000 units. Irrigated surface area increased by around 2\% compared to 2005 (53,000 hectares), with significant expansion in the North-East $(+11 \%)$ and the South $(+6 \%)$, as against decreases in the NorthWest $(-4 \%)$ and the Centre (-6\%). The most irrigated surface area is concentrated in the River Po plain: Piedmont, Lombardy and Emilia-Romagna account for 46\%, with 1,225 million hectares of irrigated land. In June 2010, the Environment Council of the EU (Council EU 2010) adopted the conclusions on water scarcity, drought and adaptation to climate change. The document recognizes that water scarcity and droughts are already a serious problem in many European regions and that the situation is expected to worsen as a consequence of climate change. It also underlines the need to promote water efficiency and water demand management through a combination of different tools.

\section{Methodology}

Irriframe software has been developed by an IT company (AltaVia srl, Italy), according to the knowledge base provided by the water boards research centre CER on behalf of Water Boards Italian Association (ANBI), which is the owner of the platform.

Irriframe consists of a set of cloud-based tools both for final water users (farmers) and for water managers (boards) to provide extended information on the best water allocation and on how to save irrigation water without decreasing the quality of crop production. It provides farms and Water Boards managers with real time information on agricultural water needs.

Irriframe integrates cloud data obtained from different sources (meteo, farm and GIS data), by means of a sound knowledge base (water balance algorithm) and it makes the irrigation scheduling available on different communication channels like Web, Smartphone and traditional phones.

\footnotetext{
${ }^{1}$ AltaVia srl \& INEA-CRA consultant

Bologna, Italy

consulting@gianfrancogiannerini.it

${ }^{2}$ Consorzio per il Canale Emiliano Romagnolo (CER)

Bologna, Italy

genovesi@consorziocer.it
} 
Real time water balances are also clustered to build up maps on water requests along the hydraulic networks.

\subsection{Project's Milestones}

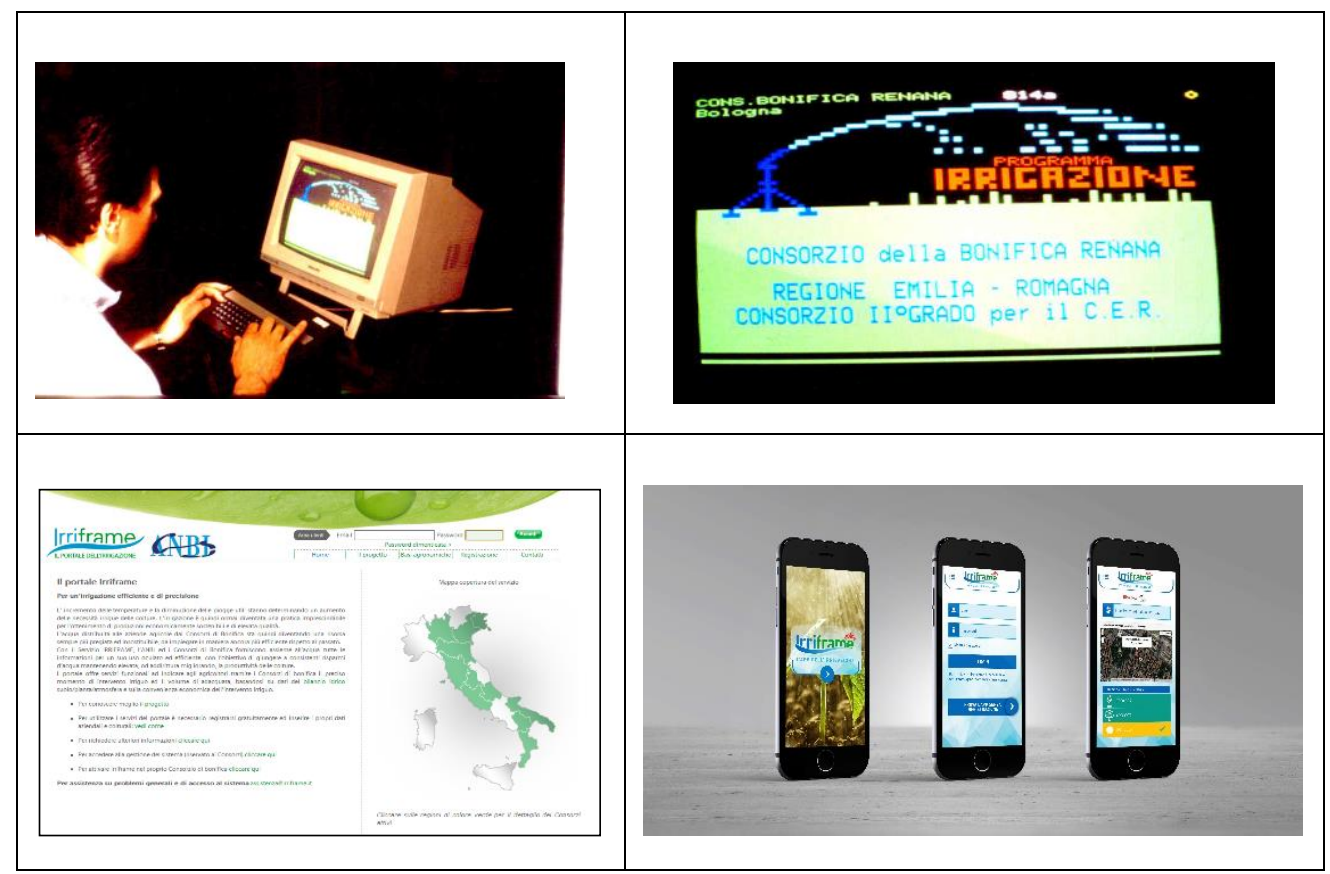

Figure 1. Three milestones for Irriframe: on the top Videotex ('80s), bottom left the Web and bottom right the App for smart phones

Started in 1984 (Giannerini 1993) with public founding to test telematics in agriculture (Videotex), Irrinet is ported on the Web in 1999 to be the first interactive agricultural service on the Internet.

In 2003 (Rossi et al. 2004) it is extended with GIS support and a SMS interface (IrriSMS).

During 2007 it involves thousands of farms, covering almost 22\% of the irrigated area in Emilia Romagna region in the northern Italy.

In 2010 (Giannerini et al. 2011 and 2013) it gets the new label "Irriframe", and is extended to the whole country through the Water Boards Italian Association (ANBI).

In 2014 Irriframe obtains the support of the Italian Ministry of Agriculture (MIPAAF) in order to extend the platform in new areas as a tool for the management of the EU's rural development policy concerning water.

Up to now, Irriframe is the irrigation support service with the larger number of real user in Europe.

\subsection{The Diffusion of Irriframe}

At present (2015) Irriframe is available in 15 Italian regions on more than 7 millions of hectares managed by 67 Water Boards (Figure 2). 


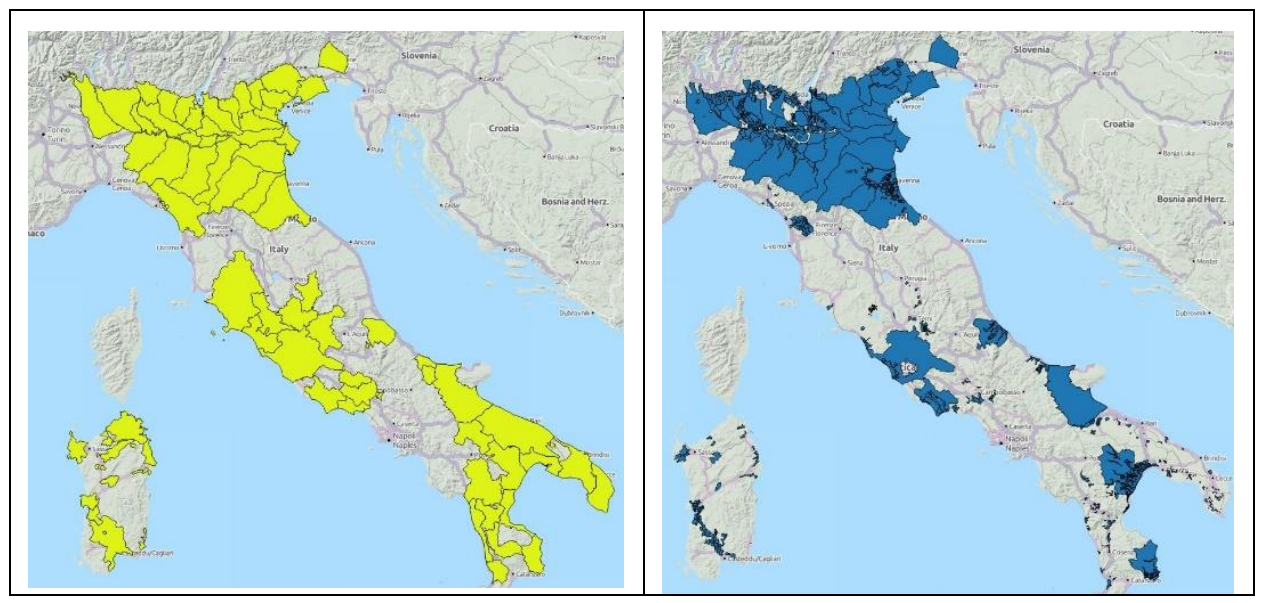

Figure 2. Water Boards involved in the project (left) and Irriframe services coverage of the irrigable areas in Italy (right)

The number of unique users registered in the service is 3.105 , and the number of farms involved is 3.866 because a user may register more than one farm i.e. the agricultural extentionists. More than 10k plots (fields) are managed by the system all over the country. Table 1 shows some figures about the 2014 irrigation season.

Table 1. Irriframe facts (season 2014)

\begin{tabular}{lr}
\hline & Number \\
\hline Unique users & 3.105 \\
Farms & 3.866 \\
Plots & 10.813 \\
IrriSMS sent & 19.299 \\
Water boards involved & 67 \\
\hline
\end{tabular}

\subsection{IT Infrastructure}

Irriframe has been developed by AltaVia on .NET 4, ASP.NET MVC and Microsoft SQLServer2012 and is hosted on cloud servers.

The platform fully implements the REST methods through the ASP.NET MVC framework.

The Model-View-Controller (MVC, Figure 3) architectural pattern separates an application into three main components: the model, the view, and the controller.

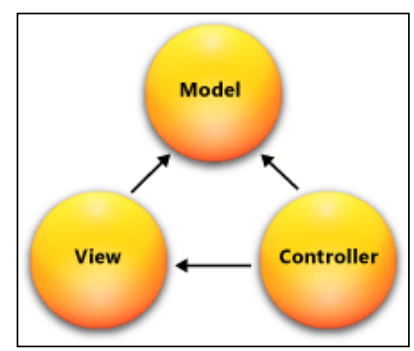

Figure 3. MVC architectural pattern

The MVC framework allows the Test-driven development (TDD) methodology, a software development process that relies on the repetition of a very short development cycle: first the developer writes an (initially failing) automated test case that defines a desired improvement or new function, then 
produces the minimum amount of code to pass that test, and finally refactors the new code to acceptable standards.

REST stands for Representational State Transfer and it is a method for retrieving content from an HTTP endpoint. REST's most notable feature is that it is stateless. In other words, each call has all the necessary information for the server to process the request. REST allows to develop applications which are easy to maintain, flexible and amenable to change.

The architecture of Irriframe is outlined in Figure 4.

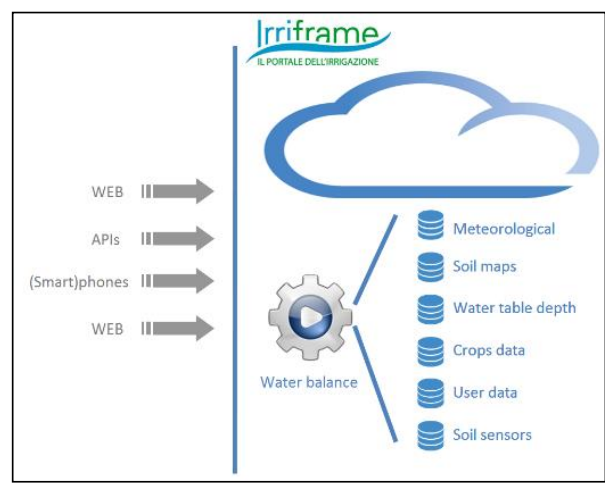

Figure 4. Irriframe platform architecture

The Irriframe services can be accessed by the different kinds of users in many ways. Final water users browse the information via Web and a smart phone APP. For the water managers Irriframe can be integrated with the Water Boards GIS applications by means of the REST direct calls.

\section{Fruition of Information by Final Users}

\subsection{Water users}

Irriframe provides a real-time irrigation scheduling: day-by-day information on how much and when to irrigate farm crops (Figure 5 on the right).

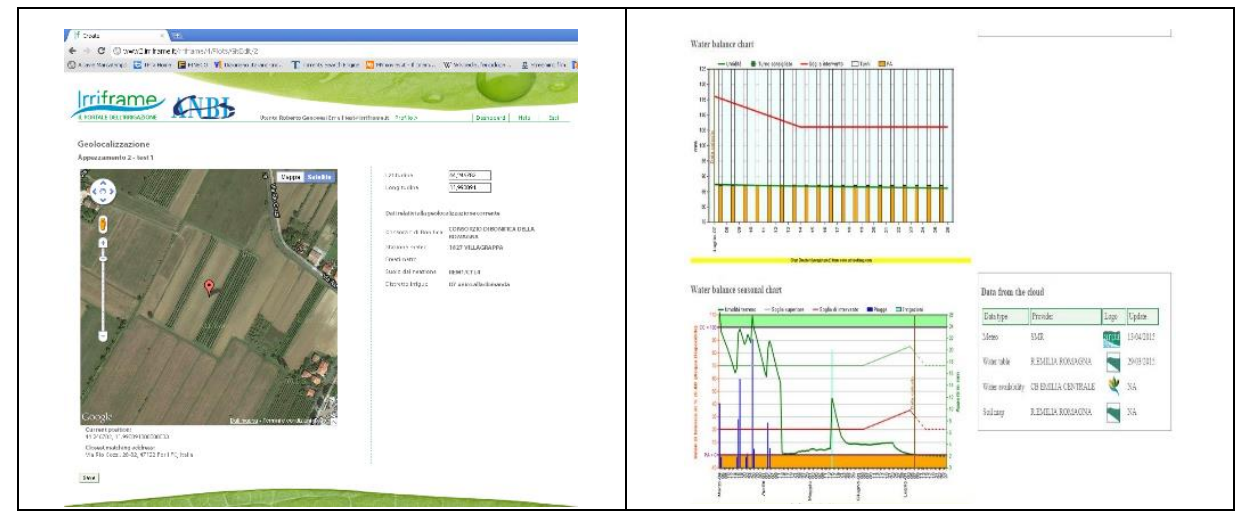

Figure 5. Screenshots of the Irriframe Web interfaces

Through the web interface the users can fully interact with the system storing plot geolocation, crop, soil and irrigation system information (Figure 5 on the left). Users can also register the local rainfalls, irrigation gifts and crop start dates to tailor the irrigation scheduling. The system is able to integrate local soil water sensors data too. On the cloud the user data is integrated with meteorological information, water availability and water table depth, allowing the system to build up the daily irrigation schedule in real time.

The final users can browse the irrigation scheduling in textual or chart format for all their crops via Web or APP. A notification is automatically sent by SMS or on the Smartphones when a new crop irrigation is predicted. 
The irrigation scheduling consists of predicted evapotranspiration (daily consumption), next irrigation day and water irrigation amount (Figure 6).

This basic scheduling is integrated with economical aspects like profitability of the irrigation gift (cost of the intervention compared with the apprised increment of yield) and the level reached of seasonal water amount allowed for that crop. In some Italian regions irrigation water volumes constraints have been established to access the EU grants.

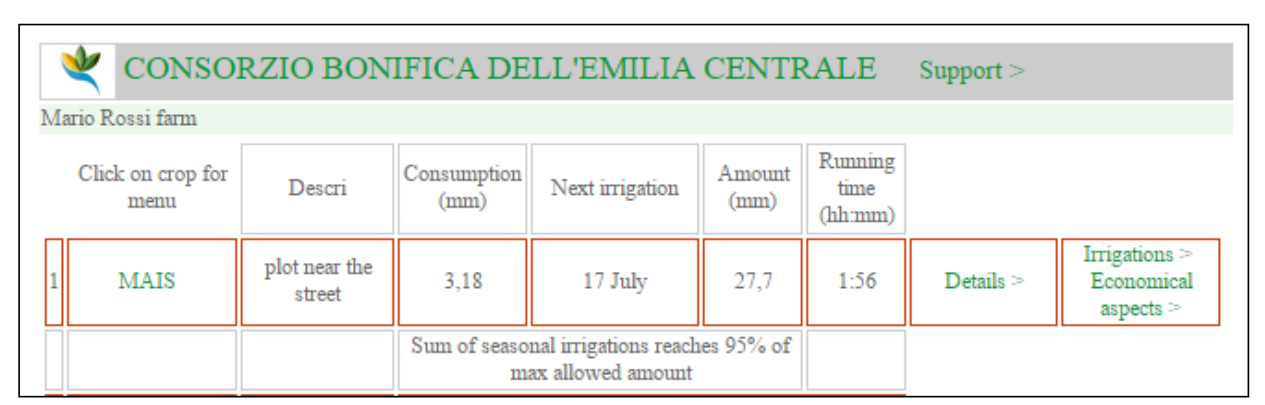

Figure 6. Close up of Irriframe water dashboard: irrigation scheduling for an user crop

\subsection{Big Data for Water Managers}

The Irriframe platform is able to store during the season all the water balances in a big data repository to calculate the water needs of an irrigation district for the past and 15 days ahead (Figure 7 left). This allows water managers to build short-term scenarios to appraise the evolution of a district's water demand.

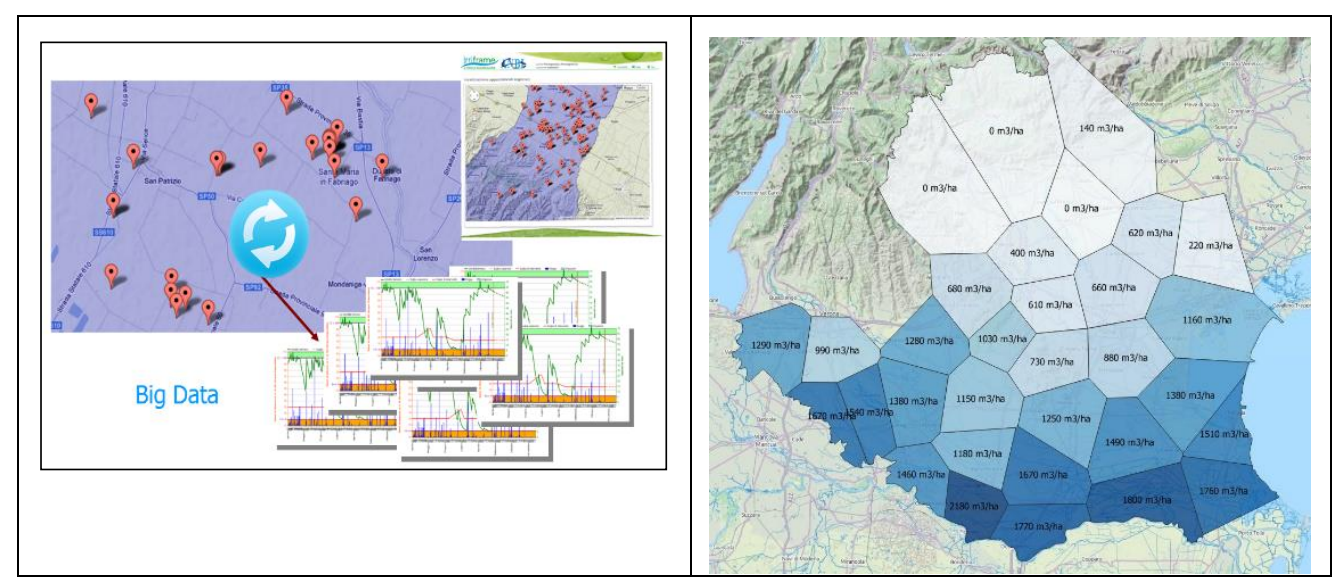

Figure 7. Big data repository of the water balances to apprise crop water requirement at district level

Information about the spatial and temporal variability of crop water requirements is provided to water managers to implement a more efficient irrigation distribution at a district level (Figure 7. right)

\subsection{Irriframe Mobile}

The Web pages have a light graphical structure and can be well displayed on a mobile browser. The same information is automatically sent via SMS to many more farmers: most of them are registered into the system by technicians and do not need Internet connection to get the irrigation scheduling.

The main functionalities of the platform can also be accessed by an APP for Android and IOS called "Irriframe Voice" (Figure 8). 


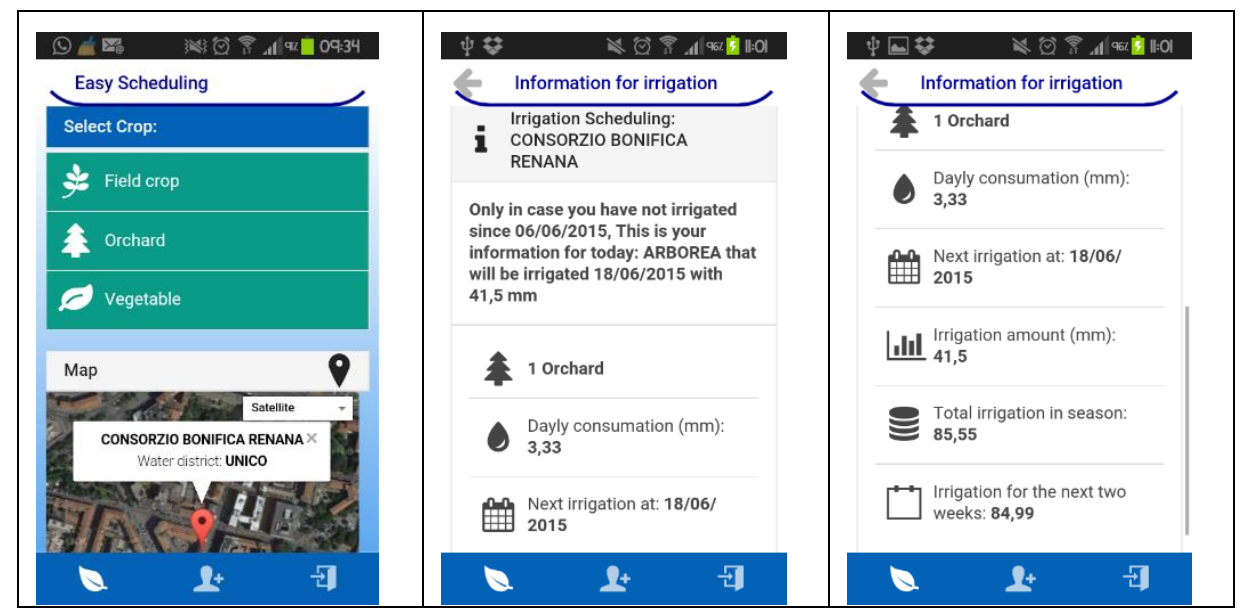

Figure 8. Screenshots of Irriframe Voice APP for Android and IOS

\section{Concluding Remarks}

Irriframe's awareness is very high in Italy and most of the farms involved with Best Practice Guidelines and/or Quality insurance use it daily. Some regional Guidelines mention Irriframe as a supporting tool to fulfill the water conditionality of the European Regional Development Fund regulation and respecting Irriframe's irrigation scheduling is mandatory for many farmers.

The platform exhibits very low management costs which are supported by the local Water Board and the service is provided for free to the final users. The operating cost of the Irriframe platform is around $0.02 € /$ ha for a whole irrigation season.

As far as the technical point of view is concerned the development group is working both on a closer integration with open GIS information layers that may reduce the amount of data the users are requested to register in the system and the use of satellite information to determine the effective crop coefficients $\left(\mathrm{K}_{\mathrm{c}}\right)$ for the water balance calculation.

\section{Acknowledgement}

The knowledge base of the platform has been developed by Canale Emiliano Romagnolo (CER).

Starting from 2014 the implementation of Irriframe on the Water Boards irrigable areas is co-funded by the Italian Ministry of Agriculture (MIPAAF) with the technical support of the Agricultural and Economy Research Council (CREA).

\section{References}

Battilani, A. and Mannini, P. 1992 'The influence of water table depth and rootstock on growth habit of peach' Acta Horticulturae 315:23-30. doi: 10.17660/actahortic.1992.315.3

Battilani, A. and Mannini, P. 1993 'Effects of water table on potato crop growth and yield' Acta Horticulturae 335:405-411. doi: 10.17660/actahortic.1993.335.49

Battilani, A. and Mannini, P. 1994 'Influence of water table depth on the yield and quality of processing tomatoes' Acta Horticulturae 376:295-298. doi: 10.17660/actahortic.1994.376.38

Battilani, A. and Ventura, F. 1996 'Influence of water table, irrigation and rootstock on transpiration rate and fruit growth of peach trees' Acta Horticulturae 449:521-528.

doi: $10.17660 /$ actahortic.1997.449.72

Council of the European Union 2010 'Water scarcity, drought and adaptation to climate change. Draft Council conclusions' Brussels 4 June 2010.

Giannerini G., Genovesi R. 2011 'Irrinet: IT services for farm water management, a large scale implementation in Italy' EFITA 2011 Conference Proceedings, Prague, Czech Republic 11-14 July 2011. 
Giannerini G., Mannini P., Genovesi R. 2013 'Irriframe as Italian national platform for water management' EFITA-WCCA-CIGR Conference "Sustainable Agriculture through ICT Innovation", Turin, Italy, 24-27 June 2013.

Giannerini, G. 1993 'Renana Model: a model for irrigation scheduling employed on a large scale' Second Workshop on Crop Water Models:15th Congress on Irrigation and Drainage. The Hague, Netherlands.

Giannerini, G. 2004 'IT services for water management' The NewAgInternational ConferenceandExibition Rome, 19th march.

Rossi F., Nardino, M., Mannini, P., Genovesi, R. 2004 'IRRINET Emilia Romagna: Online decision support on irrigation. Online Agrometeological Applications with Decision Support on the Farm Level' Cost Action 718. pp. 99-102. 